\title{
Ecological Distribution, Reproductive Characteristics, and In Situ Conservation of Malus sieversii in Xinjiang, China
}

\author{
Meiling Yang ${ }^{1}$ \\ College of Life Sciences, Nankai University, Tianjin, 300071, China; and \\ College of Horticulture and Landscape, Tianjin Agricultural University, \\ Tianjin, 300384, China
}

\author{
Fang Li ${ }^{1}$, Hong Long, Weiwei Yu, Xiuna Yan, Bin Liu, Yunxiu Zhang, \\ and Guorong Yan ${ }^{2}$ \\ College of Horticulture and Landscape, Tianjin Agricultural University, \\ Tianjin, 300384, China
}

\author{
Wenqin Song ${ }^{2}$ \\ College of Life Sciences, Nankai University, Tianjin, 300071, China
}

Additional index words. ecological distribution, seed germination, pollen germination, in situ protection, Malus sieversii

\begin{abstract}
As a wild apple species native to central Asia, Malus sieversii (Ledeb.) Roem. is distributed in a wide region covering most of the Tienshan Mountains. Malus sieversii is a useful genetic pool for apple breeding since rich with diversity. In this paper, we first describe the species range of this endangered species. We then describe an in situ reserve that has been established. We also investigated some reproductive characteristics of $M$. sieversii including pollen germination, seed dormancy, and seed viability. Both stratification and seedcoat removal efficiently released seed dormancy and accelerated seed germination. Pollen germination rate is around $60 \%$. Our data suggest that injurious insects and human activities, rather than reproductive characters, limit the renewal of $M$. sieversii.
\end{abstract}

Malus sieversii (Ledeb.) Roem. is a wild apple species native to Central Asia. Its provenance includes the region of the Tienshan Mountains, extending from China to Kyrgyzstan and Kazakhstan. It has been recognized as one of the major progenitors of Malus $\times$ domestica, the domesticated apple (Forsline and Aldwinckle, 2004). Malus sieversii is a very diverse species, exhibiting many of the qualities of $M$. ×domestica

\footnotetext{
Received for publication 20 May 2016. Accepted for publication 17 June 2016 .

M.Y., F.L., H.L., X.Y., B.L., Y.Z., G.Y., and W.S took part in field investigation and in situ conservation. M.Y., X.Y., and Y.Z. carried out pollen germination studies. M.Y., F.L., and W.Y. participated in seed germination analysis. H.L. drafted the manuscript. H.L. and G.Y. participated in the design of the study. W.S. designed and finalized the manuscript. All authors read and approved the final manuscript.

We thank Kang Liao (Xinjiang Agricultural University) for his cooperation in data analysis. We acknowledged Gayle Volk (USDA ARS -NCGRP) for her carefully improvement of the expression and English language. This study was supported by Agricultural Financial Special Fund of Xinjiang Uygur Autonomous Region, China (WH000202).

${ }^{1}$ These authors contributed equally to this article.

${ }^{2}$ Corresponding authors. E-mail: yanguorong@ eyou.com; songwq@nankai.edu.cn.
}

reduced, and it is critical to protect this precious genetic resource (Volk et al., 2005). Conservation of plant genetic resources is achieved by protection of populations in nature (in situ) or by preservation of samples in gene banks (ex situ) (Cohen et al., 1991). The latter are essential for users of germplasm who need ready access, although it costs more money and time. Ex situ conservation of $M$. sieversii has been established in the United States using $M$. sieversii seeds collected from the wild in Kazakhstan and the Kyrgyz Republic (Volk et al., 2005). In situ conservation, which can be more economical, should also be considered as a conservation strategy.

To determine the distribution of geographical populations of $M$. sieversii and its growth status in Xinjiang, we made field practice for six times. After recording and analyzing the data, we drew a map for distribution of $M$. sieversii in Xinjiang. This map is the firsthand data for its detailed distribution, which is important for geographic research of the wild apple trees. We also set a garden for in situ conservation and renewal of $M$. sieversii. This is one of the few gardens for wild apple tree protection and utilization in the world. Moreover, we investigated reproductive characters of $M$. sieversii, including vigor of pollen and seed. These experimental data and observation of growth status in $M$. sieversii suggest that injurious insects and human activities, rather than reproductive characters, limit the renewal of $M$. sieversii.

\section{Materials and Methods}

Field investigation. Field investigations were performed twice a year in 2012, 2013, and 2014. Flower buds were collected between late April and early May and seeds were collected between late July and early August from collection sites in the following Xinjiang counties: Huocheng (Daxigou), Gongliu, Xinyuan (preserved base), and Nalati (in Xinyuan). In Emin and Tuoli counties, we investigated the distribution of $M$. sieversii.

In situ conservation. To protect $M$. sieversii in situ, a barbed wire fence was placed around an area of $700 \mathrm{hm}^{2}$ in Xinyuan, at an elevation of around $1400 \mathrm{~m}, \mathrm{~N}: 43^{\circ} 37^{\prime} 90^{\prime \prime}$, E: $83^{\circ} 58^{\prime} 01^{\prime \prime}$, altitude $1291.30 \mathrm{~m}$. This site includes seven valleys, and all these valleys were distributed with $M$. sieversii.

Pollen and seed germination. In April of 2012, 2013, and 2014, we collected floral buds of $M$. sieversii at the sample sites. Flower buds were transported to Tianjin, China, and pollen were collected when the flowers opened.

Culture medium for pollen germination was $10 \%$ sucrose, $0.01 \%$ boric acid, and $0.01 \%$ agar. Pollen were scattered evenly on sterilized culture medium on a clean slide and germinated at $25^{\circ} \mathrm{C}$. The shape and germination of pollen was observed using an Olympus BX53 microscope (Olympus, Japan, Tokyo). The pollen germination rate was calculated by randomly selecting no fewer 

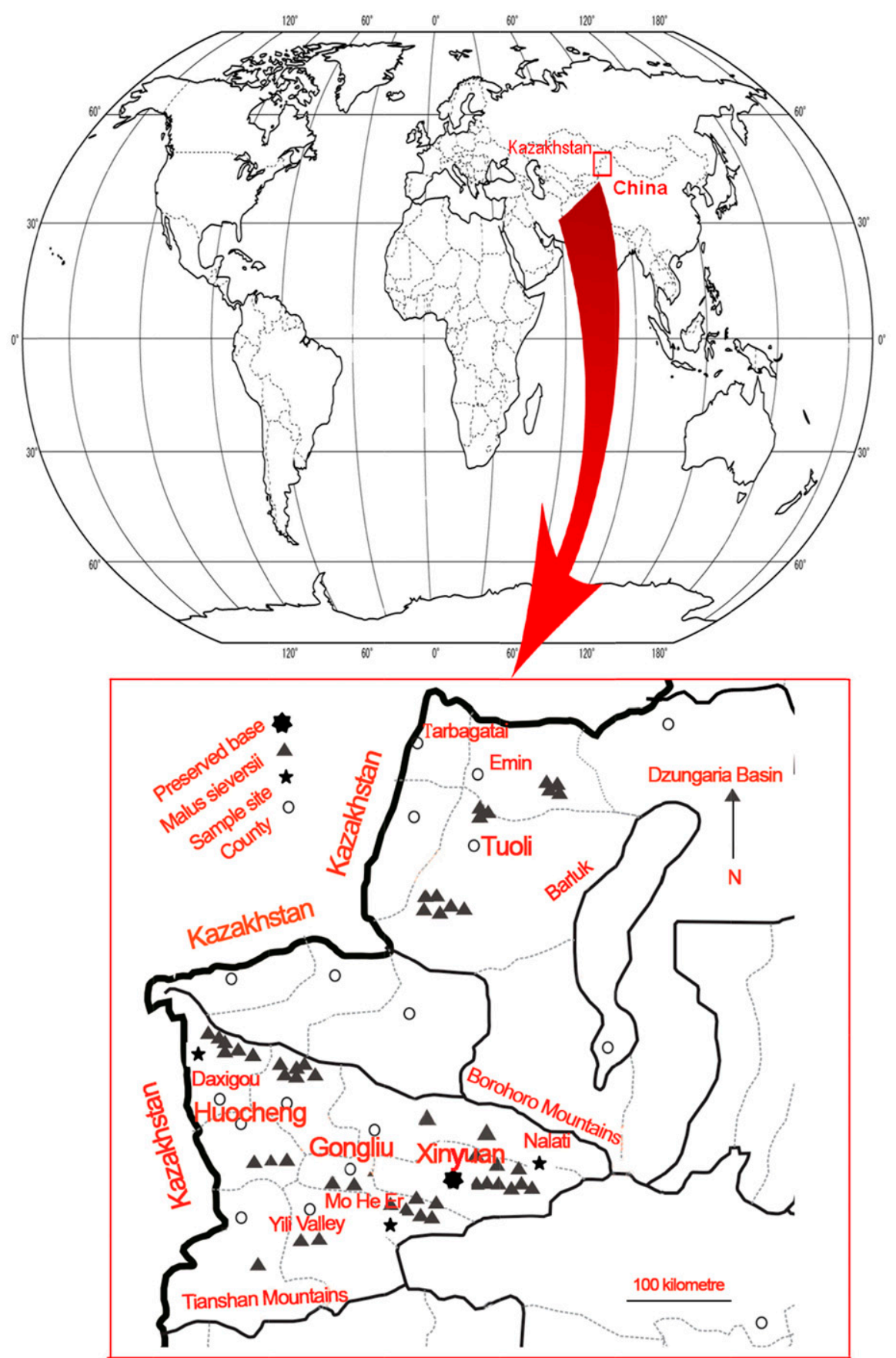

Fig. 1. Distribution of Malus sieversii in Xinjiang. Yili valley occupied a triangle region that distributed with $M$. sieversii.

than 600 pollen grains. Pollen germination rate $(\%)=$ pollen germination number of each field vision/total pollen number of each field $\times 100 \%$.

Images were taken using a SPOT-idea camera (Sterling Heights, MI), and analyzed using Image Pro Plus software (Media Cybernetics, Inc., Rockville, MD).

Seed viability. Nearly 5000 seeds from 50 wild $M$. sieversii trees were collected from different sites over six collection trips (201214). Seeds were stored at $-20{ }^{\circ} \mathrm{C}$ after collection until use. To break seed dormancy, we put seeds into plastic bags full of wet sand (sand moisture content 14.26\%) and stored time (from the beginning of the dormancybreaking treatment to the time in which the last seed germinated), germination vigor (peak ratio of maximum seeds germinated and the total seed number during germination), and germination rate (the ratio of all seeds germinated and the total seed number in the end of germination, lasting till duration time) were recorded.

\section{Results}

Malus sieversii is discontinuously distributed in the Tienshan Mountains. Malus sieversii is a deciduous broad-leaf tree that grows in the temperate zone with a rainy growing season and winters that are not severely cold. In Xinjiang, $M$. sieversii is distributed mainly in the Yili valley, but also in the southern region of the Tarbagatai Mountains and in the west of the Barluk Mountains. Six collection trips were performed, targeting seven distinct areas of Xinjiang. The observed native populations of $M$. sieversii are discontinuously distributed (Figs. 1 and 2).

This distribution suggests that the species range is affected by local climate conditions. Wild $M$. sieversii populations were primarily localized to west-deflected warm, moist air flows specific to the centrally region of the Tienshan Mountains and western Dzungaria Basin. The damp climate in Yili valley is suitable for the growth of $M$. sieversii. The average annual precipitation is over $500 \mathrm{~mm}$ and the lowest temperature is $-10{ }^{\circ} \mathrm{C}$. The wild apple tree formed pure stands, mixed with Prunus armeniaca Lam. and Picea schrenkiana Fisch et Mey. var. tianschanica (Rapi) Cheng et Fu.

The Nalati Grassland is located to the east of the town of Nalati in Xinyuan County, at an elevation of $1487 \mathrm{~m}$. The surrounding Tienshan Mountains extend in "V" shape to the west, with fragmentary distribution of $M$. sieversii on the sunny southern slopes. Associated plants include $P$. armeniaca Lam., Caragana fruten (L) koch, and Populus euphratica Oliv. Few plants were grown on shady slope. Due to the heavy grazing in this area, cover plants were less than usual (Fig. 2A).

The M. sieversii population in $\mathrm{Mo} \mathrm{He} \mathrm{Er}$, Gongliu occupied $2100 \mathrm{hm}^{2}$, altitude 1100 $1630 \mathrm{~m}$. This population is located at the foot of the Tienshan Mountains, south of Yili River, with inclined topography from southeast to northwest. The trees are scatted and distributed in a narrow and long belt along the slope (Fig. 2B).

Malus sieversii occupies an area in Emin of $280 \mathrm{hm}^{2}$, elevation $1040-1450 \mathrm{~m}$. The temperature in this region is lower than that in others, and the climate is drier. The apple trees are distributed in a scattered pattern and are shorter (Fig. 2C).

The natural reserve in Tuoli protects the wild fruit trees in this region. This region covered $650 \mathrm{hm}^{2}$, elevation $700-1500 \mathrm{~m}$. Prunus amygdalus Batsch is the major accompanying plant of $M$. sieversii, growing together in forests. In the low elevation 

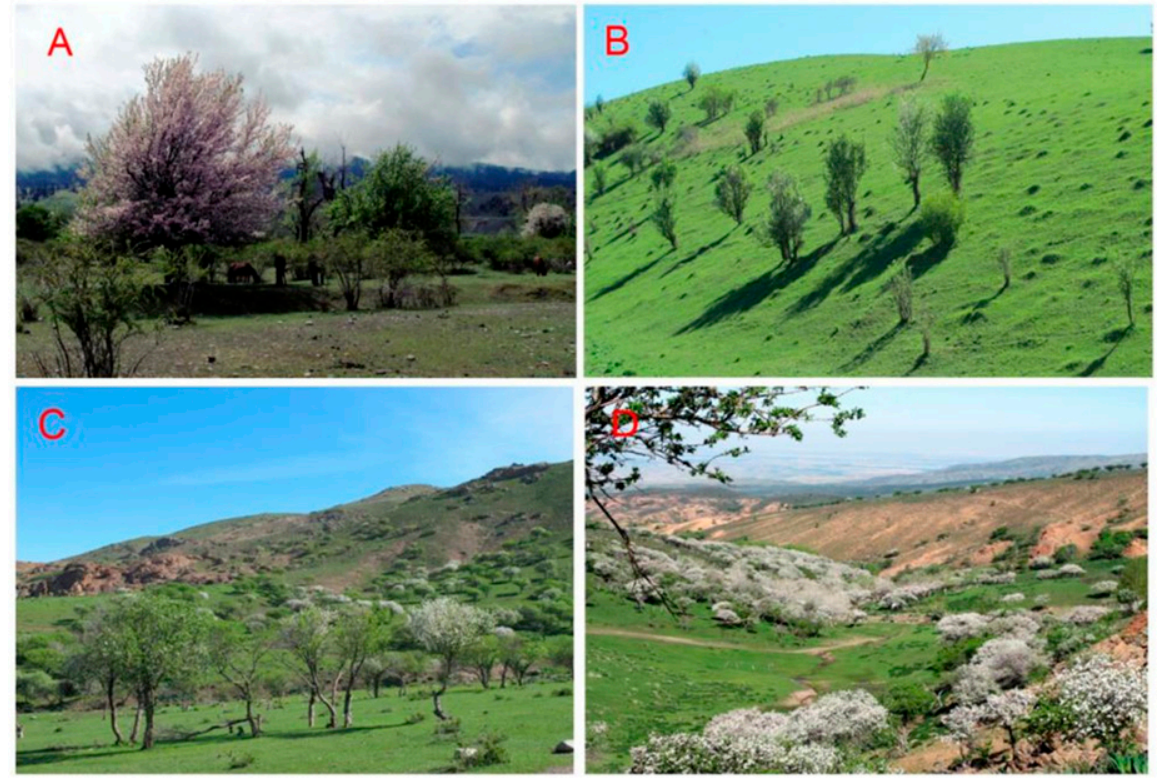

Fig. 2. Different populations of Malus sieversii in Xinjiang. (A) Nalati, Xinyuan, (B) Mo He Er, Gongliu, (C) Emin, and (D) Tuoli.

Table 1. Geographic Coordinates of each Malus sieversii collection site. Geographic coordinates were recorded according to field investigation and climatological data.

\begin{tabular}{llcccccc}
\hline & \multicolumn{3}{c}{ Position } & & \multicolumn{3}{c}{ Annual temperature } \\
\cline { 2 - 4 } $\begin{array}{l}\text { Distribution } \\
\text { site }\end{array}$ & Latitude & Longitude & $\begin{array}{c}\text { Elevation } \\
(\mathrm{m})\end{array}$ & $\begin{array}{c}\text { Precipitation } \\
(\mathrm{mm})\end{array}$ & $\begin{array}{c}\text { Lowest } \\
\left({ }^{\circ} \mathrm{C}\right)\end{array}$ & $\begin{array}{c}\text { Avg } \\
\left({ }^{\circ} \mathrm{C}\right)\end{array}$ & $\begin{array}{c}\text { Highest } \\
\left({ }^{\circ} \mathrm{C}\right)\end{array}$ \\
\hline Nalati & $\mathrm{N}: 43^{\circ} 30^{\prime} 83^{\prime \prime}$ & $\mathrm{E}: 84^{\circ} 10^{\prime} 94^{\prime \prime}$ & $\mathrm{H}: 1,487$ & 271 & 24.50 & 9.81 & -2.92 \\
Mo He Er & $\mathrm{N}: 43^{\circ} 15^{\prime} 22^{\prime \prime}$ & $\mathrm{E}: 82^{\circ} 52^{\prime} 58^{\prime \prime}$ & $\mathrm{H}: 1,530$ & 253 & 24.17 & 9.16 & -5.17 \\
Emin & $\mathrm{N}: 46^{\circ} 21^{\prime} 04^{\prime \prime}$ & $\mathrm{E}: 83^{\circ} 58^{\prime} 37^{\prime \prime}$ & $\mathrm{H}: 1,040$ & 220 & 22.58 & 7.66 & -7.92 \\
Tuoli & $\mathrm{N}: 46^{\circ} 08^{\prime} 31^{\prime \prime}$ & $\mathrm{E}: 83^{\circ} 32^{\prime} 40^{\prime \prime}$ & $\mathrm{H}: 960$ & 390 & 20.75 & 6.54 & -7.58 \\
Daxigou & $\mathrm{N}: 44^{\circ} 42^{\prime} 72^{\prime \prime}$ & $\mathrm{E}: 80^{\circ} 78^{\prime} 81^{\prime \prime}$ & $\mathrm{H}: 1,181$ & 220 & 18.50 & 10.89 & -3.75 \\
\hline
\end{tabular}

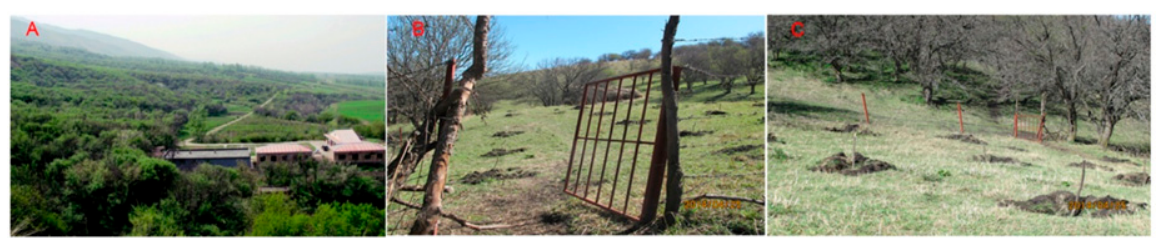

Fig. 3. Preserved base of Malus sieversii in Xinyuan County. (A) View of the base. (B) The gate and fence of the garden. (C) Biannual/triennial seedlings transplanted in the garden.

Table 2. Survival rate of seedlings and transplanting of $M$. sieversii in different years. Survival rate of 5-year-old plant in 2012 reached to $88.50 \%$.

\begin{tabular}{lccc}
\hline Yr & Seedling & 2-yr-old plant & 5-yr-old plant \\
\hline 2011 & $19.00 \%$ & $70 \%$ & N/A \\
2012 & N/A & $45.90 \%$ & $88.50 \%$ \\
2013 & N/A & N/A & $50.00 \%$ \\
\hline
\end{tabular}

$\mathrm{N} / \mathrm{A}=$ not applicable

region, the ground was sparsely covered with grass (Fig. 2D). Geographic coordinates of each region for collection of $M$. sieversii are listed in Table 1.

In situ conservation of Malus sieversii promotes its growth and renewal of its population. Our in situ conservation of $M$. sieversii focused on establishing and utilizating a preserved base in Xinyuan County of XinJiang YiLi Kazak Autonomous Prefecture
(Fig. 3A). This base covered an area of 700 $\mathrm{hm}^{2}$, with an elevation of $1240-1650 \mathrm{~m}$. In the base, we set aside a garden to regenerate $M$. sieversii (Fig. 3B and C).

Artificial regeneration of the wild $M$. sieversii tree was performed mainly through seedling propagation and by transplanting. Threats in the external environment, such as cattle consumption or human trampling, could reduce its ability of natural $M$. sieversii regeneration. We set aside a garden in the preserved base with an area of $5 \mathrm{hm}^{2}, 1476 \mathrm{~m}$, $\mathrm{N}: 43^{\circ} 37^{\prime} 53^{\prime \prime}, \mathrm{E}: 83^{\circ} 53^{\prime} 50^{\prime \prime}$ in May 2011. At this time, 20 seedlings were transplanted into the garden, and only four trees survived. In Oct. 2011, 200 seedlings were transplanted, and the survival rate was $70 \%$. Moreover, we sowed 3000 seeds in 300 holes, 10 seeds/ hole (survival rate is $20 \%$ ), as a supplement.
Transplanting in autumn had a higher survival rate than that of in spring, perhaps due to the higher rainfall levels. In May 2012, 249 twoor three-year-old seedlings were transplanted, of which 135 plants survived. In May 2013 500 two-year-old seedlings were transplanted into the in situ garden and 135 trees survived (survival rate was 46\%). One hundred threeyear-old plants and 260 five-year-old plants were transplanted in Oct. 2013 (survival rate was $50 \%$ and $71 \%$, respectively) (Table 2 ).

Despite our efforts to select a site that minimal threats, the trees in the in situ reserve suffered from both diseases and pests. Agrilus mali Mats., jewel beetle from Buprestidae, caused great damage to $M$. sieversii (Fig. 4A), and resulted in a $30 \%$ reduction of the total planting in the garden. The spatial distribution pattern of the larvae of $A$. mali was aggregate (Liu et al., 2007). Larva of $A$. mali consumed phloem of the wild apple tree, causing the injured branch to undergo necrosis (Fig. 4B and C). With adult emergence, the branch desiccated. The pest diffused seriously, especially in lower elevation regions of the in situ site. Agrilus mali is extremely injurious to the wild apple trees and tends to destroy them. In 2005, we found that $A$. mali started to damage individual cultivated apple trees in a farmer's orchard. In 2006, it was diffused among wild apple trees. In 2007, parts of the branches were dried and withered. By cutting and burning the dried branches, the trees grew better with fewer diseased plants in 2008. In Spring 2009, we performed pesticide control on large amount of branches $M$. sieversii, injecting $40 \%$ Omethoate $10 \times$ solutions via drillingholes on xylems of stems to kill larva. Moreover, pesticide was used to control adult stages of the insect as well. Biological control (parasitic wasps) were been used during 2011-12 to successfully control $A$. mali in the garden. Wild populations seriously suffered from the insect.

Pollen germination revealed high vigor of male reproduction. Pollen grains of M. sieversii vary in shape and size. Dry pollen are oblong oval (Fig. 5A), and the pollen grains become spherical after absorbing water in the culture medium (Fig. 5B). The length of the polar axis is longer than the equatorial axis. The length of polar axis is between 31 and $45 \mu \mathrm{m}$, while the equatorial axis is between 28 and $41 \mu \mathrm{m}$. The ratio of polar axis and equator is between 1.0 and 1.3 (Table 3). According to the length of polar axis, equatorial axis and the ratio, the pollens can be divided into oval or bean shaped.

We used in vitro germination assays to assess pollen viability. After germinating 2 , 3 , and $4 \mathrm{~h}$, pollen germination rate and length of pollen tube were observed and calculated (Fig. 5C and D; Table 4).

The pollen germination level was as high as $59 \%$, and the length of pollen tube was $250 \mu \mathrm{m}$ in $2 \mathrm{~h}$. At $3 \mathrm{~h}$, the germination level was similar to that of $2 \mathrm{~h}(59 \%)$, and the pollen tube length was $277 \mu \mathrm{m}$. After $4 \mathrm{~h}$, the pollen germination level was $69 \%$, and the pollen tube length was $566 \mu \mathrm{m}$, significantly higher than germination levels and pollen tube lengths than those observed at 2 and $3 \mathrm{~h}$. 

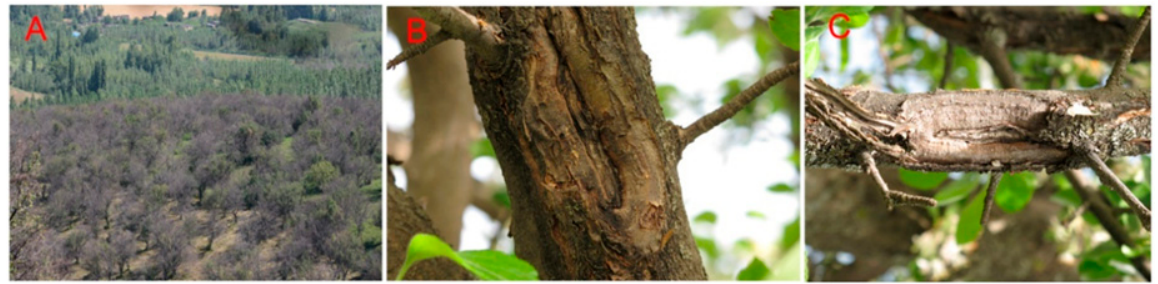

Fig. 4. Wild apple trees suffered by Agrilus mali. (A) The forest. (B and C) Injured branches.

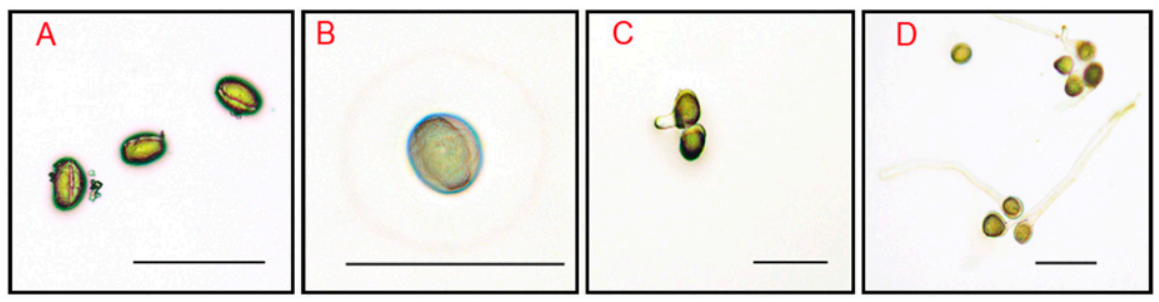

Fig. 5. Process of pollen germination. (A) Dried pollen. (B) Swelled pollen. (C) Pollens start to germinate. (D) Elongation of pollen tubes. Bars $=50 \mu \mathrm{m}$.

Table 3. Malus sieversii pollen length of polar axis and equator axis. Samples from different populations were used in the measurement of pollens.

\begin{tabular}{lccr}
\hline Sample site & Polar axis $(\mu \mathrm{m})$ & Equator axis $(\mu \mathrm{m})$ & Ratio $(\%)$ \\
\hline Na La Ti & 38.186 & 35.293 & 1.105 \\
Mo He Er & 35.972 & 30.769 & 1.172 \\
Emin & 38.148 & 35.020 & 1.092 \\
Tuoli & 43.360 & 38.074 & 1.140 \\
\hline
\end{tabular}

Table 4. Pollen germination rate and tube length.

\begin{tabular}{lcc}
\hline Germination time $(\mathrm{h})$ & Pollen germination level $(\%)$ & Pollen tube length $(\mu \mathrm{m})$ \\
\hline 2 & 58.9 & 250.0 \\
3 & 59.1 & 276.9 \\
4 & $69.0^{* *}$ & $566.3^{* *}$ \\
\hline
\end{tabular}

$t$ test was used for statistical analysis, $* *$ significantly different from $2 / 3(P<0.01, \mathrm{n}=20)$.

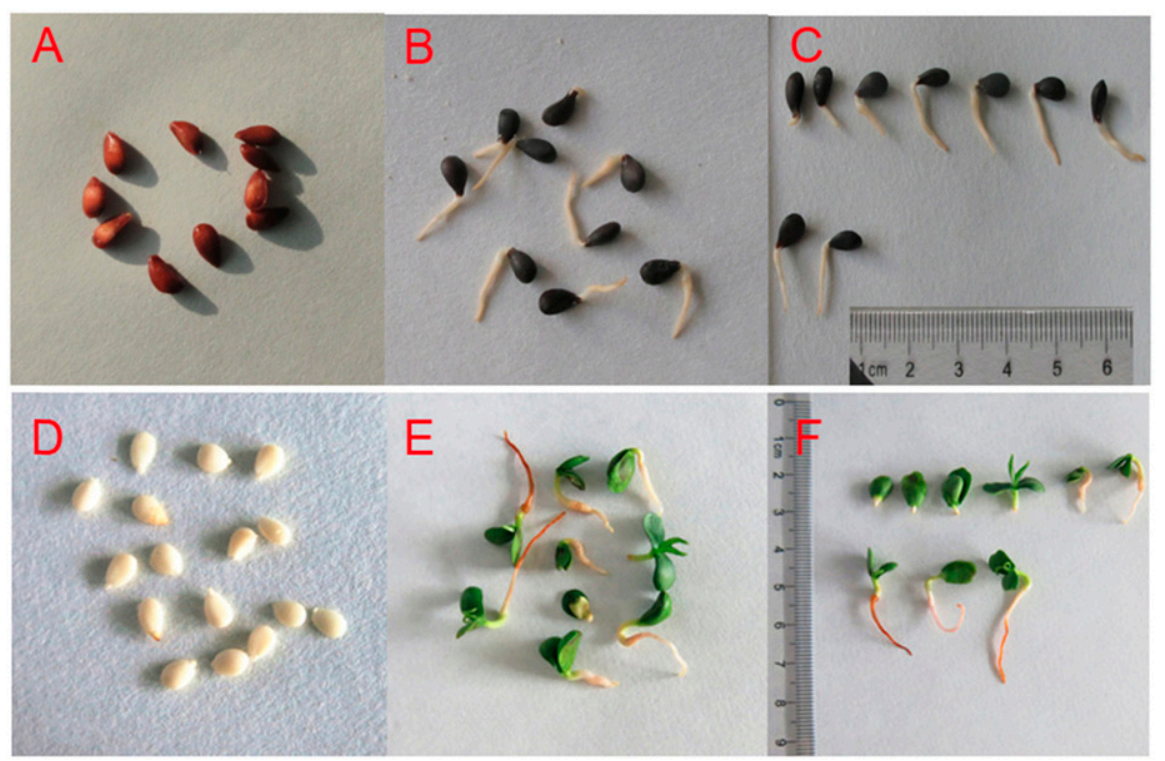

Fig. 6. Malus sieversii seeds (2 years old) with seedcoats (A) and with seedcoats removed (D). Seeds were stratified at $4{ }^{\circ} \mathrm{C}$ for $90 \mathrm{~d}$ before germination $(\mathbf{B}$ and $\mathbf{C})$ or germinated immediately following seedcoat removal $(\mathbf{E}$ and $\mathbf{F})$. Images were taken $5 \mathrm{~d}$ after germination $(\mathbf{B}-\mathbf{C}$ and $\mathbf{E}-\mathbf{F})$.

Both stratification and seedcoat removal break seed dormancy and accelerate seed germination. Seeds stored at $4{ }^{\circ} \mathrm{C}$ in wet sand and those buried outside in the winter successfully germinated (Fig. 6A-C). When stored at $4{ }^{\circ} \mathrm{C}$, germination level of 2-yearstored seeds and 3-year-stored seeds was $95 \%$ and $96 \%$, respectively. The seeds started to germinate after a $60 \mathrm{~d}$ the stratification treatment. Total seed germination duration was 69 and $70 \mathrm{~d}$, the vigor of germination were $46 \%$ and $45 \%$ in seeds that were stored 2 and 3 years, respectively (Table 5). The germination status for seeds buried under earth was similar to that above, except it took longer to break the dormancy ( 85 and $87 \mathrm{~d}$, Table 5).

We also tested the germination status for the seeds harvested in the current year (without stratification treatments) and did not observe any germination. To accelerate seed germination, we removed the seedcoat from sets of seeds (Fig. 6E and F). The germination percentage is $96 \%$, similar to that of stratified seeds.

\section{Discussion}

Plant geographic distribution varies with climate (Kelly and Goulden, 2008). In ancient times, M. sieversii was grown and flourished in the Yili valley and in Kyrgyzstan and Kazakhstan with the protection of Tienshan Mountains. Currently, climate is a major factor influencing the natural distributions of wild apple trees. In China, M. sieversii does not thrive in cold regions, which limit its distribution. According to our field investigation, the regions suitable for the growth of $M$. sieversii are low elevation regions that are humid and warm.

Seed germination is very important for plant reproduction and prerequisite for in situ conservation. We compared three different methods of seed germination. Stratification $\left(4^{\circ} \mathrm{C}\right.$ storage) resulted in the highest levels of seed germination. Primary seed dormancy is initiated during development. Developing seeds rarely germinate, and when precocious germination does occur, it is frequently associated with deficiencies in ABA synthesis or sensitivity (Bewleyl, 1997; Finch-Savage and Leubner-Metzger, 2006). With cold treatment, gibberellins release (coat) dormancy and promote germination (Kucera et al., 2005; LeubnerMetzger, 2001). Seedcoat removal is also a good method quickly germinating some types of seeds, although the germination levels may be decreased. The rapid germination may be related to the removal of hormones that accumulate in the seedcoat.

Different populations of $M$. sieversii in Xinjiang showed nonhomogeneous distribution. Natural renewal of seedlings and suckering plants was not adequate to recover the populations. In recent years, vegetation destruction caused by farming-related activities has resulted in a decline in the vigor of wild apple trees. Large amount of fruits were collected every autumn for the use of fruit 
Table 5. Germination of 2 and 3 year's seed of Malus Sieversii. $4{ }^{\circ} \mathrm{C}$ treatment was performed in refrigerator with seeds in wet sand. The stratification treatment was performed by burying seeds outdoors between December and February Duration refers to the time from the beginning of the dormancy-breaking treatment to the time in which the last seed germinated. Germination vigor refers to the peak ratio of maximum seeds germinated and the total seed number during germination. Germination rate refers to the ratio of all seeds germinated and the total seed number in the end of germination, lasting till duration time.

\begin{tabular}{lccccc}
\hline Treatment & $\begin{array}{c}\text { Storage } \\
\text { time }(\mathrm{y})\end{array}$ & $\begin{array}{c}\text { Days to } \\
\text { germinate }(\mathrm{d})\end{array}$ & $\begin{array}{c}\text { Duration } \\
(\mathrm{d})\end{array}$ & $\begin{array}{c}\text { Germination } \\
\text { vigor }(\%)\end{array}$ & $\begin{array}{c}\text { Germination } \\
\text { rate }(\%)\end{array}$ \\
\hline $4{ }^{\circ} \mathrm{C}$ & 2 & 61 & 69 & 46 & 95 \\
$4{ }^{\circ} \mathrm{C}$ & 3 & 63 & 70 & 45 & 94 \\
Stratification & 2 & 70 & 85 & 51 & 96 \\
Stratification & 3 & 70 & 87 & 47 & 94 \\
\hline
\end{tabular}

processing enterprises, which may have affected the growth and renewal of $M$. sieversii populations. Moreover, the excessive human activities such as land reclamation, overgrazing, and over-cutting damaged both mature and young plants, and affected its natural propagation. Biological factors (mainly insects) may also aggravate natural changes in the growth environment of $M$. sieversii (Yan et al., 2008).

Effective methods for protection of $M$. sieversii are necessary to improve growth environment and maintain the balance of population structure and function. Enclosure is a suitable in situ protective measure. According to our experience, the damage caused by $A$. mali was more serious in low elevation area than that in high elevation area. Therefore, we set up an enclosure in a high elevation area to reduce the possible pernicious influence by injurious insects and human activities.

In summary, our results showed that there were not significant differences among the seed and pollen germination levels from different populations of $M$. sieversii. Both stratification and seedcoat removal efficiently ted seed germination. We could protect endangered $M$. sieversii populations resource by enclosure in situ. Our data suggest that injurious insects and human activities, rather than reproductive characters, limit the renewal of $M$. sieversii.

\section{Literature Cited}

Bewleyl, J.D. 1997. Seed germination and dormancy. Plant Cell 9:1055-1066.

Cohen, J.I., J.T. Williams, D.L. Plucknett, and H. Shands. 1991. Ex situ conservation of plant genetic resources: Global development and environmental concerns. Science 253:866872.

Finch-Savage, W.E. and G. Leubner-Metzger. 2006. Seed dormancy and the control of germination. New Phytol. 171:501-523.

Forsline, P.L. and H.S. Aldwinckle. 2004. Evaluation of M. sieversii seedling populations for released seed dormancy successfully accelera- disease resistance and horticultural traits. Acta Hort. 663:529-534.

Geibel, M., K.J. Dehmer, and P.L. Forsline. 2000. Biological diversity in Malus sieversii populations from central Asia. Acta Hort. 538:43-49.

Kelly, A.E. and M.L. Goulden. 2008. Rapid shifts in plant distribution with recent climate change. Proc. Natl. Acad. Sci. USA 105:11823-11826.

Kucera, B., M.A. Cohn, and G. Leubner-Metzger. 2005. Plant hormone interactions during seed dormancy release and germination. Seed Sci. Res. 15:281-307.

Leubner-Metzger, G. 2001. Brassinosteroids and gibberellins promote tobacco seed germination by distinct pathways. Planta 213:758-763.

Liu, A., Alim, Y. Xu, X. Zhang, Y. Wang, S. Jiao, M. Du, E. Ye, and Kereman. 2007. Study on spatial distribution patten of Agrilus mali larvas in wild fruit forests in Xinjiang. J. Northwest For. Univ. 22:92-94. (in Chinese with English abstract).

Liu, L., F. Liang, P. Liu, M. Gao, and J. Guo. 2008. Primary study on pollination biology of Malus sieversii (Ledeb).Roem. J. Xinjiang Agr. Univ. 31:26-30. (in Chinese with English abstract).

Sińska, I. 1989. Interaction of ethephon with cytokinin and gibberellin during the removal of apple seed dormancy and germination of embryos. Plant Sci. 64:39-44.

Volk, G.M., C.M. Richards, A.D. Henk, and A. Reilley. 2009. Novel diversity identified in a wild apple population from the Kyrgyz Republic. Hortscience 44(2):516-518.

Volk, G.M., C.M. Richards, A.A. Reilley, A.D. Henk, P.L. Forsline, and H.S. Aldwinckle. 2005. Ex situ conservation of vegetatively propagated species: Development of a seedbased core collection for Malus sieversii. Amer. Soc. Hort. Sci. 30:203-210.

Yan, G., H. Long, W. Song, and R. Chen. 2008. Genetic polymorphism of Malus sieversii populations in Xinjiang,China. Genet. Resources Crop Evol. 55:171-181. 